\title{
Article
}

\section{THEMIS observations and riometry: A data comparison with a view to proxy and prediction}

Birch, Martin John and Hargreaves, J.K.

Available at http://clok.uclan.ac.uk/19921/

Birch, Martin John and Hargreaves, J.K. (2016) THEMIS observations and riometry: A data comparison with a view to proxy and prediction. Journal of Atmospheric and Solar-Terrestrial Physics, 137 . pp. 66-75. ISSN 1364-6826

It is advisable to refer to the publisher's version if you intend to cite from the work. http://dx.doi.org/10.1016/j.jastp.2015.11.005

For more information about UCLan's research in this area go to http://www.uclan.ac.uk/researchgroups/ and search for < name of research Group>.

For information about Research generally at UCLan please go to http://www.uclan.ac.uk/research/

All outputs in CLoK are protected by Intellectual Property Rights law, including Copyright law. Copyright, IPR and Moral Rights for the works on this site are retained by the individual authors and/or other copyright owners. Terms and conditions for use of this material are defined in the policies page.

\section{CLoK}

Central Lancashire online Knowledge www.clok.uclan.ac.uk

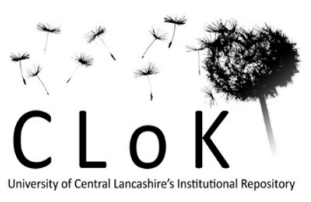


November 18, 2015

\title{
THEMIS observations and riometry: a data comparison with a view to proxy and prediction
}

\author{
M.J. Birch ${ }^{1}$ \\ J.K. Hargreaves ${ }^{2,1}$
}

(1) Jeremiah Horrocks Institute for Mathematics, Physics and Astronomy, University of Central Lancashire, Preston, UK.

(2) Department of Physics, Lancaster University, UK.

\begin{abstract}
A comparison has been made between radio absorption events observed by riometer at selected times of day and bursts of electrons observed in the midnight sector by THEMIS satellites. The correlation is found to be good for absorption in the noon and midnight sectors but poor around dawn and dusk. For noon and midnight the absorption can be estimated from the THEMIS electron flux to better than a factor of 2 in most cases. In the noon sector the absorption follows the THEMIS event by about 30 minutes on average (though with considerable variation from case to case), but by night the absorption precedes the electron flux by about 8 minutes on average. Thus, the flux at THEMIS can be predicted from the absorption in the night sector, the accuracy being better than a factor of 3 in most cases. The flux observed also depends on the location of the satellite, reducing with increasing distance down the tail. It is estimated that the source of the tail events observed in this study was at about $6 \mathrm{R}_{e}$, and comparisons are made with the established general pattern of the substorm in auroral absorption.
\end{abstract}




\section{Introduction}

Auroral radio absorption was first identified as a distinct phenomenon by Reid and Collins (1959), and early studies established its character as a sub-storm phenomenon, the absorption events being stronger and more frequent during periods of enhanced solar and geomagnetic disturbance (Holt et al., 1961). Its incidence in local time and magnetic latitude was first defined by Hartz et al. (1963), Driatsky (1966), and Hargreaves and Cowley (1967).

Jelly at el (1964) and Parthasarathy et al (1966) developed associations between the level of radio absorption and the incoming flux of electrons of energy greater than $40 \mathrm{keV}$ observed by a low-orbit satellite, and later work based on incoherent-scatter radar has shown that the amount of absorption is consistent with the resulting increase of electron density in the lower ionosphere (Hargreaves and Devlin, 1990; Birch et al., 2013).

The above comparisons between electron flux and absorption used observations on satellites passing over, or close to, the site of the riometer used for the absorption measurement. However, in verifying auroral absorption as a substorm driven phenomenon, Parthasarathy and Reid (1967) showed that dayside absorption was also related to increased particle activity in the midnight sector, though with a time delay, and Hargreaves et al (1968) verified this using data from Vela satellites some $17 \mathrm{R}_{e}$ down the magnetotail. It became clear from these studies that in a given absorption substorm the activity originated from the tail region on the night side of the Earth.

An objective of the present study is to explore these relationships in greater detail and to investigate whether the more recent observations of tail conditions using the Time History of Events and Macroscale Interactions during Substorms (THEMIS) group of satellites (Angelopoulos, 2008) might enhance knowledge of these connections or even be useful in predictions.

\section{Observations}

The THEMIS satellites were launched in February 2007. A group of five, they were designed to study magnetotail phenomena and dynamics, particularly during substorms. Among the various sensors are the Electrostatic Analyser (ESA) and the Solid State Telescope (SST). The ESA covers the electron energy range from $7 \mathrm{eV}$ to $31.2 \mathrm{keV}$, whereas the SST covers the electron energy range from $31 \mathrm{keV}$ to $719.5 \mathrm{MeV}$. We shall use mainly the $41.0 \mathrm{keV}$ and $93.0 \mathrm{keV}$ SST energy channels in this study. The SST comprises two identical instruments per satellite, each instrument measuring electrons in two opposite directions thereby forming four reception cones 
in all. Each satellite has a spin axis which is nearly orthogonal to the ecliptic plane and completes one revolution in about 3 seconds. The spin of the spacecraft, and the alignment and angular coverage of the reception cones, mean that the two SST instruments together provide almost omnidirectional measurement of the incoming electron flux, except for cones $39^{\circ}$ wide centred on the vertical and an annulus $13^{\circ}$ wide centred on the horizontal.

A 49-beam imaging riometer (IRIS), the Imaging Riometer for Ionospheric Studies (Browne et al., 1995), is used for the absorption measurements. Situated at Kilpisjärvi, Finland (geographic latitude $69.05^{\circ} \mathrm{N}$, longitude $20.79^{\circ} \mathrm{E}$, L-value 5.9 ), it is slightly equatorward of the statistical maximum of the absorption zone. Our comparisons use only the vertical beam to determine the ionospheric radio absorption at the operating frequency of $38.2 \mathrm{MHz}$. Some reference will also be made to observations by the European Incoherent Scatter (EISCAT) radar near Tromso, Norway (geographic latitude $69.9^{\circ} \mathrm{N}$, longitude $19.23^{\circ} \mathrm{E}$, L-value 6.0 ), which is about $112 \mathrm{~km}$ north-west of IRIS.

\section{A comparison between THEMIS and IRIS peaks.}

\subsection{Method of peak selection}

Comparisons with THEMIS satellite observations are restricted to periods when at least one spacecraft is between 2100 and $0300 \mathrm{LT}$ and within $3 \mathrm{R}_{e}$ of the ecliptic plane. (Though there was no range constraint down the magnetotail, all the observations were between 5.5 and $16 \mathrm{R}_{e}$ ). Within these constraints, THEMIS passes through the tail were selected for four time sectors, specifically when IRIS was located in the midnight, dawn, noon and dusk sectors (22-24, 4-6, 10-12 and 16-18 UT, or approximately 23.5-1.5, 5.5-7.5, 11.5-13.5 and 17.5-19.5 LT at Kilpisjärvi where the local time is 1.39 hours later than UT, and magnetic local time is 0.9 hours later than LT). The period from January to April 2008 was selected, a period when the satellites were predominantly in the tail region. This period includes an EISCAT radar run on 2008 March 9 (see Section 5).

For each time sector, plots of the $41 \mathrm{keV}$ flux observed at THEMIS were inspected visually, and events were selected for which the peak magnitude and time of occurrence could be clearly identified. The corresponding plots of the $38.2 \mathrm{MHz}$ radio absorption at IRIS were then inspected for activity within about an hour of each THEMIS event. If present, the magnitude and time of the associated absorption events were noted. The approach to the data analysis is illustrated 
by Figure 1 which shows a THEMIS-A event on 2008 February 15 with IRIS in the noon sector. The THEMIS-A flux peaked at $487 \mathrm{~cm}^{-2} \cdot \mathrm{s}^{-1} \cdot \mathrm{sr}^{-1} \cdot \mathrm{eV}^{-1}$ at 11:00 UT, and the absorption peaked at $0.4 \mathrm{~dB}$ at 11:21 UT. Not all the THEMIS passes were suitable for such a comparison, some being dominated by strong features of characteristic form, presumably due to the permanent Van Allen belts, and these were rejected from the data set.

\subsection{Basic statistics of the occurrence of associated features}

The initial data inspection identified 194 instances with at least one THEMIS satellite between 2100 and $0300 \mathrm{LT}$ within $3 \mathrm{R}_{e}$ of the ecliptic plane. Of these, 62 were (or seemed likely to be) affected by the strong features mentioned above. Of the remaining 132 selections, 104 showed a measurable flux event at $41 \mathrm{keV}$, and inspection of the riometer data for those times showed a clearly associated absorption event of at least $0.1 \mathrm{~dB}$ on 66 days. Inspection of the list of substorm onsets identified from the SuperMAG electrojet (SME) index (Newell et al., 2011a, 2011b) revealed that on all but 3 of the 66 days a magnetic substorm occurred within or close to the selected time period. Table 1 summarises these statistics in terms of the four selected IRIS sectors. For each comparison the event maxima (as seen in both the particle flux and the absorption) were noted, and also the times of these peaks. The observed electron densities indicate that in nearly all cases the satellite was in the plasma sheet when within 10Re.

Table 2 provides a more detailed summary of the data and shows the probability of the absorption being at least 1.0 and $0.3 \mathrm{~dB}$ over a selection of flux ranges in each of the four sectors. (On some days a flux event was observed by more than one satellite, and where that occurred all are included separately; Table 2 therefore shows more flux values in total (138) than Table $1(104)$ ). These results confirm that the relation between the two quantities is strongest for the noon and midnight sectors, as illustrated in Figure 2. For example, at noon, for a flux between 100 and $330 \mathrm{~cm}^{-2} \cdot \mathrm{s}^{-1} \cdot \mathrm{sr}^{-1} \cdot \mathrm{eV}^{-1}$ at $41 \mathrm{keV}$ we expect a $6 \%$ chance of seeing at least 1.0 $\mathrm{dB}$ absorption and a $69 \%$ chance of at least $0.3 \mathrm{~dB}$. In no case (within our selection) was there an occurrence of more than $0.3 \mathrm{~dB}$ if the THEMIS flux remained below $10 \mathrm{~cm}^{-2} \cdot \mathrm{s}^{-1} \cdot \mathrm{sr}^{-1} \cdot \mathrm{eV}^{-1}$ at $41 \mathrm{keV}$.

\subsection{Adjustment of flux for satellite position}

Figure 3 shows a mass plot of the observed flux and absorption values for the noon sector. Because of the difficulty of specifying very small values of absorption, those values less than 0.1 
$\mathrm{dB}$ are indicated by diamonds. In many cases, an event was observed by more than one satellite at different locations in the magnetotail, and where such multiple readings were obtained the values are connected by horizontal lines. It is noted that there can be considerable variations between these multiple values.

In order to determine whether these variations in flux may be due to differing locations within the nightside region, variations of flux with satellite position were investigated. No evidence was found for any systematic variation in the peak magnitude with the local time of the satellite. However, there is a significant variation with the radial distance in the ecliptic plane. This relationship was investigated using the 23 events which were observed by more than one satellite in the nightside region (2100-0300 LT, and within $3 \mathrm{R}_{e}$ of the ecliptic), all such examples being shown in Figure 4a, in which the associated observations are connected. There is clearly a tendency for the flux $(F)$ to reduce with increasing distance, suggesting a linear relation of $\log (F)$ as a function of $r$ of the form $\log F=c-k r, r$ being the geocentric distance in the ecliptic plane, $k$ the gradient, and $c$ a constant.

A value for $k$ was determined using a cumulative minimising technique in which the difference between each adjusted associated flux value was compared for a range of assumed values of $k$ (Figure $4 \mathrm{~b}$ ). This suggests a value of $\mathrm{k}$ between 0.12 and 0.16 ; a value of 0.14 was therefore assumed. To remove the influence of distance, the observed fluxes $\left(F_{r}\right)$ were therefore adjusted to $\mathrm{r}=10 \mathrm{R}_{e}\left(F_{10}\right)$ using the formula -

$$
\log \left(\frac{F_{10}}{F_{r}}\right)=0.14(r-10)
$$

(A relationship of the form $\mathrm{F}_{r} \propto 1 / \mathrm{r}^{3}$ would also be a reasonable fit.)

In order to verify that the observed flux is related to the position of the satellite as well as the strength of the associated absorption event, a partial correlation analysis was performed on the data selections for the 22-24 UT and 10-12 UT periods. The analysis uses every observation in the data set, not just those having simultaneous observations from 2 or more spacecraft. The partial correlation coefficient is usually designated $\rho_{12,3}$ where 1 and 2 are the quantities correlated and 3 is the quantity "partialled-out" by the procedure.

The results of this analysis are summarised in Table 3, in which the observed flux is $\mathrm{F}$, the absorption is A, and the radial distance of the satellite is $\mathrm{r}$. The significance of the correlation coefficient is tested using Fisher's z-transform (Fisher, 1921; Moroney, 1951), the value of z being normally distributed with standard deviation $1 / \sqrt{N-3}, \mathrm{~N}$ being the number of values. 
By this means the probability $(\mathrm{u})$ of the correlation having arisen by chance may be estimated. The parameters $\mathrm{z}$ and $\mathrm{u}$ are included in Table 3, which verifies that the associations of $\mathrm{F}$ with both $\mathrm{A}$ and $\mathrm{r}$ are very significant, whereas there is no significant association between $\mathrm{A}$ and $\mathrm{r}$.

\subsection{Detailed comparison of magnitudes.}

For comparison purposes, the observed flux is adjusted to $10 \mathrm{R}_{e}$ using equation (1). The variation of peak absorption (A) with the adjusted peak $41 \mathrm{keV}$ electron flux $\left(\mathrm{F}_{10}\right)$ is shown in Figure 5 for the four IRIS sectors. Because of their relative uncertainty, low absorption values $(<0.1 \mathrm{~dB})$ are marked with diamonds and are not included in the correlation computations. Correlation coefficients and other statistical quantities derived from these distributions are given in Table 4. There is a clear distinction in these properties between the sectors. In the noon and midnight sectors the correlation coefficients (0.74 and 0.73$)$ are highly significant, and the probability that they arose by chance is very small. In those sectors the absorption could be predicted from the observed flux to within a factor of about 1.7 standard error. For the dawn and dusk sectors the situation is quite different, with a small negative correlation which is of low significance. These times are near the diurnal minima in the occurrence of auroral absorption events, whereas the noon and midnight sectors are near occurrence maxima (Hargreaves, 1969).

\section{Peak-to-peak timing}

\subsection{The delay time between THEMIS flux peaks at $41 \mathrm{keV}$ and IRIS absorp- tion peaks}

The peak-to-peak delays between the bursts at THEMIS and the associated IRIS events for the four time sectors (midnight, dawn, noon, and dusk) are summarised in Figure 6. In nearly all cases where a valid comparison could be made it is clear that in the noon sector the absorption followed the THEMIS event in nearly every case, the median time difference being 29 minutes (with quartiles at 13 and 39 minutes). However, in the midnight sector the IRIS event preceeded that at THEMIS, with a median time difference of 8 minutes (with quartiles at 4 and 9 minutes). The time differences are not so systematic for the dawn and dusk sectors, which is perhaps not surprising given the lack of correlation between the magnitudes in those sectors. However, in the dawn sector the flux precedes the absorption in $70 \%$ of the observations and the median time difference is 20 minutes. The tendency for the flux to precede the absorption is probably 
significant in this case also.

Adding together the midnight and noon median values predicts a typical delay of 37 minutes from the night to the day absorption events. This is similar to the night-day difference estimated from absorption observations at stations widely separated in longitude (e.g Hargreaves, 1967; Pudovkin et al., 1968). Notable is the fact that in the midnight sector the absorption event precedes the burst of energetic electrons detected by the THEMIS satellite. This suggests that the source is closer to the field lines through Kilpisjarvi (at $\mathrm{L}=5.9$ ) than to those through the satellite. Figure 7 shows the satellite locations in relation to the nose of the field line $(\mathrm{L}=$ 5.9) from Kilpisjärvi for each of the midnight sector events. The only consistency is that the THEMIS event never precedes the absorption event observed at the ground, though they are simultaneous on two occasions. The source location may be variable, but this result suggests that it is usually close to 6 Earth radii. According to Liang et al. (2007) substorm dipolarisation tends to occur near the duskward edge of the magnetotail, with which Figure 7 appears to be consistent. At least half of the flux events plotted have the appearance of a spike, though several are more complex in structure.

If the observed absorption precedes the flux, riometer observations near local midnight may serve as a predictor of particle bursts in the tail. For the midnight sector, using the same approach as in Table 2, but with absorption as the primary selection variable, there are 24 THEMIS observations unaffected by belt contamination when absorption was at least $0.1 \mathrm{~dB}$, 21 of which were associated with measurable flux. These selections are summarised in Table 5. For a numerical prediction of the flux $\left(\right.$ at $\left.10 \mathrm{R}_{e}\right)$ from the observed absorption the regression equation for $\mathrm{F}_{10}$ on $\mathrm{A}$ given in Table 4 should be valid. The standard error of estimate in this case would be a factor of about 2.5. (The overall variation of flux observed in the 22-24 UT sector was a factor of about 100.)

\subsection{Time delay between satellites}

The 23 cases when there were 2 or more THEMIS satellites in the selected tail region frequently show a pattern of activity which is similar in general character though with differences in detail. Figure 8 shows an example. For 16 such events, time differences for apparently similar, welldefined features were studied. However, these fail to show any consistency regarding the direction and speed of a presumed propagating event. This may be in part due to the time resolution of the observations (either 1.6 or 3.2 minutes). Out of 29 comparisons from the 16 events, $62 \%$ of 
the time differences were no more than 3 minutes and only two were more than 6 minutes.

\section{$5 \quad$ Spectral characteristics}

D-region observations were made using the EISCAT radar on the morning of 2008 March 9 (Birch et al, 2013). Some examples of the spectra derived from the electron-density profiles are illustrated in Figure 9, together with the spectra observed by THEMIS-D. It is clear that in the period from 0253 until 0638 UT there is reasonable agreement between the two spectral estimates, even though the satellite is separated by 10 to 15 Earth radii in distance and 6 to 10 hours of local time from the estimated nose of the field line through the EISCAT radar. The gradient of the spectrum is almost constant during this period, the flux steadily decreasing with increasing energy. However, by 0736 UT the spectrum is beginning to harden, with a maximum appearing between 50 and $100 \mathrm{keV}$, and by $0816 \mathrm{UT}$ the change is pronounced.

To examine this matter further, the ratio between the fluxes at 93.0 and $41.0 \mathrm{keV}$ was taken as an indicator of the hardness of the spectrum. The values were taken at the peaks for each energy, not necessarily at exactly the same time. Mass plots of hardness against the local time at the satellite and against its geocentric distance show no clear trends, suggesting that the observed variation of intensity with range is not accompanied by any systematic variation of spectrum.

Figure 10 shows the time variation of hardness parameter from THEMIS-D and -E, and also the same parameter derived from the EISCAT data, for the times when there was sufficient precipitation for an estimate to be made. (THEMIS fluxes $<0.1 \mathrm{~cm}^{-2} \cdot \mathrm{s}^{-1} \cdot \mathrm{sr}^{-1} \cdot \mathrm{eV}^{-1}$ were excluded from the spectral ratio computations, which resulted in the gaps in the plots.) As indicated by Figure 9 there is reasonable agreement between THEMIS and EISCAT in the early morning, but the ratios diverge after about $0700 \mathrm{UT}$, with the spectrum deduced from EISCAT hardening considerably towards noon, a change which is not present in the THEMIS data. These results are consistent with the tendency towards spectral hardening in the day sector reported by Hargreaves and Devlin (1990). A likely cause is acceleration by interaction with whistler-mode VLF waves as the energetic electrons move eastward under gradient-curvature drift (Horne et al., 2003). 


\section{Discussion}

Previous studies using THEMIS have compared results with properties of luminous aurora (e.g. Gabrielse et al., 2009; Keiling et al., 2009; Mende et al., 2009; Nishimura, 2010; Pu et al., 2010; Xing et al., 2010; Zou et al., 2010; Liu et al., 2011). The energies used in the present work are considerably higher than those producing luminosity, and the comparison with auroral radio absorption is more appropriate at these energies.

That the particles causing auroral radio absorption on the night side of the Earth might be produced by the annihilation of magnetic field in the tail of the magnetosphere was first suggested by Axford et al. (1965), and Reid and Parthasarathy (1966) found examples where the pattern of particle flux on the IMP- 1 satellite at $28 \mathrm{R}_{e}$ agreed closely with the variation of radio absorption observed from the ground. Collis et al., (1984) showed that electron fluxes in the range $20-160 \mathrm{keV}$ at geosynchronous orbit $\left(6.6 \mathrm{R}_{e}\right)$ could be predicted from riometer data to an accuracy of $50 \%$ for the larger absorption events $(>2 \mathrm{~dB})$, the samples being taken from the whole day. More recently, Spanswick et al. (2007) have observed a close relation between rapidonset events (spikes excluded) seen with the CRESS satellite at $8 \mathrm{R}_{e}$ in the tail and absorption at $\mathrm{L}=6.6$ observed by riometers near midnight in the Canadian sector. Clilverd et al. (2012) and Ovalle et al. (2012) have made comparisons between riometers in the Antarctic and fluxes observed by THEMIS in the tail, finding some clear associations between flux and absorption. According to riometer studies, the latitude of maximum absorption occurrence is at about $67^{\circ}$ magnetic latitude $(\mathrm{L}=6.5)$ during the period around midnight and into the morning, though before about $2100 \mathrm{LT}$ the maximum is more poleward at $72^{\circ}$ or beyond (Hargreaves and Cowley, 1967). There is, however, considerable variation from case to case.

The timing of absorption events at the ground is also variable. As a rule they are seen first at about $\mathrm{L}=5$ (magnetic latitude $63^{\circ}$ ), from whence they spread both poleward and equatorward (Hargreaves et al., 1975). The latitude of the onset depends somewhat on the level of geomagnetic activity as indicated by $\mathrm{K}_{p}$, there being some equatorward displacement if $\mathrm{K}_{p}$ is large. The progression of absorption from the night to the day side has been noted on many occasions. There seems little doubt that the trapped electrons move eastward by the process of gradient-curvature drift in the terrestrial magnetic field (e.g. Horne et al., 2003). However, since the movement of structural features in the precipitated flux is eastward after midnight but westward before that, some other factor must be involved in the precipitation process, perhaps a propagating hydrodynamic wave (Hargreaves, 1968). This is still an open question, however. 
A previous comparison between $\geq 45 \mathrm{keV}$ electron flux observed at $17 \mathrm{R}_{e}$ by Vela satellites in the tail and auroral absorption at a number of riometers in the auroral zone (Hargreaves et al., 1968) found that the absorption event at $\mathrm{L}=7$ in the midnight sector generally precedes the increase of flux at Vela by 20 to 30 minutes, implying an outward motion. It was suggested that the field lines reaching $17 \mathrm{R}_{e}$ typically connect to the ground at about $\mathrm{L}=14\left(74^{\circ}\right.$ invariant latitude). It was also estimated that the flux of energetic electrons entering the atmosphere was considerably greater than the associated flux at $17 \mathrm{R}_{e}$.

In many cases a weak bay-like event, the "pre-onset bay", is observed before the main event. These can be extensive in longitude, and are first seen at a relatively high latitude, from which they drift equatorward within the range $\mathrm{L}=16$ to 4 , with most individual cases covering between one and five or six units of L. The median speed over the ground is $100-200 \mathrm{~m} / \mathrm{s}$. It was suggested (Hargreaves et al., 1975; Ranta et al., 1981) that this motion may be due to ExB drift of plasma in the magnetotail under the influence of the cross-tail electric field. The main event often appears first near the eastern end of the bay, which would generally be in the midnight sector.

The "spike event" is another absorption feature that may be significant. This is of short duration and often marks the beginning of an absorption substorm as seen on the nightside of the Earth. Spike events generally, though not always, move poleward, though there can also be an east-west component. In the European sector, which includes Kilpisjärvi, the speeds are in the range 200-3000 m/s over the ground (Ranta et al., 1981; Hargreaves et al., 1997; Ranta et al., 1999). Taken together, these observed absorption features constitute the so-called "reversedy" event (Hargreaves et al., 1975). Features of spikey appearance were present in many of the THEMIS events studied.

Recent observations by satellites in the tail, in some cases compared with ground-based observations, have produced a range of ideas about processes and their locations, some at or even beyond 25 Earth radii, others in the so-called "near-Earth" region at about 7-10 Earth radii (Petrukovich and Yahnin, 2006; Lui, 2007; Xing et al., 2010). The present comparison between auroral absorption features near midnight and energetic particle bursts in the tail, in which the absorption event seen at about 6 Earth radii always precedes the THEMIS event, clearly supports a near-Earth source for the main substorm event. However, the studies of pre-onset absorption activity indicate that the onset is preceded by the inward movement of a feature from a much greater distance, whose arrival closer to the Earth then triggers the main event. The existence of two apparent sources of energetic particles was pointed out by Ashour-Abdalla 
et al. (2011), the first one at a reconnection region producing particles of relatively low energy, and a subsequent one producing particles of higher energy due to dipolarisation of the magnetic field closer to the Earth. The implication of separate low- and high-energy fluxes produced at different times and different locations within the magnetotail would appear to be consistent with the pattern of auroral absorption and apparent sources as described above.

\section{Summary}

There is a significant association between the $41 \mathrm{keV}$ electron flux observed by THEMIS in the magnetotail and the auroral radio absorption at $38.2 \mathrm{MHz}$ at Kilpisjärvi in the noon and midnight sectors. The association is much weaker in the morning and evening sectors.

The electron flux also depends on the location, falling off exponentially in proportion to the distance down the tail.

At noon and midnight the absorption could serve as a proxy for the tail flux within a factor of 2 in most cases.

The tail flux usually precedes the absorption at noon but follows the absorption at midnight, the median times being 29 and 8 minutes respectively, though there can be considerable variation from case to case. The tail flux could therefore serve as a predictor of noon absorption, and the midnight absorption as a predictor of tail flux. In the latter case the magnitude would be predicted to an accuracy better than a factor of 3 in most cases.

The relative timing in the midnight sector suggests outward movement of the flux event down the tail from a source close to $6 \mathrm{R}_{e}$.

A comparison with spectra derived from incoherent scatter radar observations shows reasonable agreement between the spectra from THEMIS in the tail and the radar when in the post-midnight to early morning sector. Thereafter the spectrum of precipitating electrons hardens relative to the THEMIS measurement. No evidence was found for any systematic variation of spectral hardness with location in the tail.

Acknowledgements The authors would like to thank Dr. B.J.I. Bromage (University of Central Lancashire) for provision of the EISCAT VHF radar time allocation, the observations from which were used to derive the EISCAT spectra used in Section 5. Assistance in the reduction of the EISCAT data was provided by Dr. I. McCrea and other members of the EISCAT Support Group at the Rutherford Appleton Laboratories, UK. Thanks are also extended to 
Dr. J. Lewis (University of California, Berkeley), THEMIS software manager, for assistance in deriving the ESA/SST fluxes and spectra. For the substorm list we gratefully acknowledge the SuperMAG initiative and the SuperMAG collaborators.

\section{References}

Angelopoulos, V., 2008. The THEMIS mission. Space Sci. Rev., 141, 5-34.

Ashour-Abdalla, M., El-Alaoui, M., Goldstein, M.L., Zhou, M., Schriver, D., Richard, R., Walker, R., Kivelson, M.G., Hwang, K-J., 2011. Observations and simulations of non-local acceleration of electrons in magnetotail magnetic reconnection events. Nature Physics, 7, 360365 .

Axford, W.I., Petschek, H.E., Siscoe, G.L., 1965. Tail of the magnetosphere. J. Geophys. Res. $70,1231-1236$.

Birch, M.J., Hargreaves, J.K., Bromage, B.J.I., 2013. Properties of auroral radio absorption patches observed in the morning sector using imaging riometer and incoherent-scatter radar. J. Atmos. Terr. Phys., 105-106, 262-272.

Browne, S., Hargreaves, J.K., Honary, B., 1995. An imaging riometer for ionospheric studies. Electronics and Communication Engineering Journal. 7, 209.

Clilverd, M. A., Rodger, C.J., Rae, I.J., Brundell, J.B., Thomson, N.R., Cobbett, N., Verronen, P.T., Menk, F.W. 2012, Combined THEMIS and ground-based observations of a pair of substorm associated electron precipitation events, J. Geophys. Res., 117, A02313, doi:10.1029/2011JA016933

Collis, P.N., Hargreaves, J.K., Korth, A., 1984. Auroral radio absorption as an indicator of magnetospheric electrons and of conditions in the disturbed auroral D-region. J. Atmos. Terr. Phys., 46, 21-38.

Driatsky, V.M., 1966. Study of the space and time distribution of auroral absorption according to observations of the riometer network in the arctic. Geomagnetism and Aeronomy, v6, p.828.

Fisher, R. A., 1921. On the probable error of a coefficient of correlation deduced from a small sample, Metron, 1, 332 . 
Gabrielse, C., Angelopoulos, V., Runov, A., Frey, H.U., McFadden, J., Larson, D.E., Glassmeier, K.H., Mende, S., Russell, C.T., Apatenkov, S., Murphy, K.R., and Rae, I.J., 2009. Timing and localization of near-Earth tail and ionospheric signatures during a substorm onset. J. Geophys. Res. 114, A00C13.

Hargreaves, J.K., 1967. Auroral motions observed with riometers: movements between stations widely separated in longitude. J. Atmos. Terr. Phys. 29, 1139.

Hargreaves, J.K. Cowley, F.C., 1967. Studies of auroral radio absorption events at three magnetic latitudes: 1. Occurrence and statistical properties of the events. Planet. Space Sci., 15, 15711583.

Hargreaves, J.K., 1968. Auroral motions observed with riometers: latitudinal movement and a median global pattern. J. Atmos. Terr. Phys., 80, 1461-1470.

Hargreaves, J.K., Hones, E.W., Singer, S., 1968. Relations between bursts of energetic electrons at 17 Earth-radii in the magnetotail and radio absorption events in the ionospheric D-region. Planet. Space Sci., 16, 567.

Hargreaves, J.K., 1969. Auroral absorption of HF radio waves in the ionosphere: a review of results from the first decade of riometry. Proc. IEE, v57, No8, p.1348.

Hargreaves, J.K., Chivers, H.J.A., Axford, W.I., 1975. The development of the substorm in auroral radio absorption. Planet. Space Sci., 23, 903-911.

Hargeaves, J.K., Devlin, T., 1990. Morning sector electron precipitation events observed by incoherent scatter radar. J. Atmos. Terr. Phys. 52, 193.

Hargreaves, J.K., Browne, S., Ranta, H., Ranta, A., Rosenburg, T.J., Detrick, D.L., 1997. A study of substorm-associated nightside spike events in auroral absorption using imaging riometers at South Pole and Kilpisjärvi. J. Atmos. Solar-Terrestrial Phys. 59, 853-872.

Hartz, T.R., Montbriand, L.E., Vogan, E.L., 1963. A study of auroral absorption at $30 \mathrm{Mc} / \mathrm{s}$. Canadian Journal of Physics, 41, 581.

Holt, O., Landmark, B., Lied, F., 1961. Analysis of riometer observations obtained during polar radio blackouts. J. Atmos. Terr. Phys., 23, 229. 
Horne, R.B., Glauert, S.A., Thorne, R.M., 2003. Resonant diffusion of radiation belt electrons by whistler-mode chorus. Geophys. Re. Letters, 30, 9, 1493.

Jelly, D.H., McDiarmid, I.B., Burrows, J.R., 1964. Correlation between intensities of auroral absorption and precipitating electrons. Can. J. Phys., 42, 2411.

Keiling, A., Angelopoulos, V., Weygand J. M., Amm, O., Spanswick, E., Donovan, E., Mende, S., McFadden, J., Larson, D., Glassmeier, K.H., Auster, H.U., 2009. THEMIS ground-space observations during the development of auroral spirals, Ann. Geophys., 2007, 4317-4322.

Liang, J., Liu, W.W., Spanswick, E., Donovan, E.F., 2007. Azimuthal structures of substorm electron injection and their signatures in riometer observations, JGR, 112, doi:10.1029/2007JA012354.

Liu, J., Angelopoulos, V., Kubyshkina, M., McFadden, J., Glassmeier, K.H., Russell, C.T., 2011. Revised timing and onset location of two isolated substorms observed by Time History of Events and Macroscale Interactions During Substorms (THEMIS). J. Geophys. Res., 115, A12309.

Lui, A.T.Y., 2007. Solving a four-decade-old mystery. John Hopkins APL Technical Digest, 27, $3,233-238$.

Mende, S., Angelopoulos, V., Frey, H.U., Donovan, E., Jackel, B., Glassmeier, K.H., McFadden, J.P., Larson, D., Carlson, C.W., 2009. Timing and location of substorm onsets from THEMIS satellite and ground based observations. J. Geophys. Res., 27, 2813-2830.

Moroney, M. J., 1951. Facts From Figures, Pelican Books, Harmondsworth, U.K.

Newell, P. T., and J. W. Gjerloev, 2011. Evaluation of SuperMAG auroral electrojet indices as indicators of substorms and auroral power, J. Geophys. Res., 116, A12211, doi:10.1029/2011JA016779.

Newell, P. T., and J. W. Gjerloev, 2011. Substorm and magnetosphere characteristic scales inferred from the SuperMAG auroral electrojet indices, J. Geophys. Res., 116, A12232, doi:10.1029/2011JA016936.

Nishimura, Y, Lyons L., Zou, S., Angelopoulos, V., Mende S, 2010. Substorm triggering by new plasma intrusion: THEMIS all-sky imager observations, J. Geophys. Res., 115, A07222, doi: 10.1029/2009JA015166. 
Ovalle, E.M., Vidal, S.E., Foppiano A.J., Weatherwax, A., Stepanova, M.V., Comparison of antarctic riometer radio wave absorption and Themis missions energetic electron fluxes, Advances in Space Research, 49(11), 1538-1543, 2012.

Parthasarathy, P., Berkey, F.T. and Ventakeson, D., 1966. Auroral zone electron flux and its relation to broadbeam radiowave absorption. Planet.Space Sci. 14, 65.

Parthasarathy, R., Reid, R.C., 1967. Magnetospheric activity and its consequences in the auroral zone. Planet. Space Sci., 15, 917.

Petrukovich, A.A., and Yahnin, A.G., 2006. The substorm onset location controversy. Space Science Reviews, 122, 81-87.

Pu, Z.H., Chu, X.N., Cao, X., Mishin, V., Angelopoulos, V., Wang, J., Wei, Y., Zong, Q.G., Fu, S.Y., Xie, L., Glassmeier, K.H., Frey, H., Russell, C.T., Liu, J., McFadden, J., Larson, D., Mende, S., Mann, I., Sibeck, D., Sapronova, L.A., Tolochko, M.V., Saifudinova, T.I., Yao, Z.H., Wang, X.G., Xiao, C.J., Zhou, X.Z., Reme, H., Lucek, E., 2010. THEMIS observations of substorms on 26 February 2008 initiated by magnetotail reconnection. J. Geophys. Res., $115, \mathrm{~A} 02212$

Pudovkin, M.I., Shumilov, O.I. and Zaitzeva, S.A, 1968. Dynamics of the zone of corpuscular precipitations. Planet. Space Sci., 16, 881.

Ranta, H., Ranta, A., Collis, P.N., Hargreaves, J.K., 1981. Development of the auroral absorption substorm: studies of the pre-onset phase and sharp onset using an extensive riometer network. Planet. Space Sci., 29, 1287-1313.

Ranta, H., Ranta, A., Hargreaves, J.K., 1999. Small-scale structure of ionospheric absorption of cosmic noise during pre-onset and sharp onset phases of an auroral absorption substorm. Geophysica (Geophysical Society of Finland), 35, 45-57.

Reid, G.C. and Collins, C., 1959. Observations of abnormal VHF radio wave absorption at medium and high latitudes. J. Atmos. Terr. Phys., 14, 68.

Reid, G.C., and Parthasarathy, R., 1966. Ionosphere effects of energetic electron bursts in the tail of the magnetosphere. J. Geophys. Res., 71, 3267-3272.

Spanswick, E., Donovan, E., Friedel, R., Korth, A., 2007. Ground based identification of dispersionless electron injections. Geophys. Res. Letters, 34, L03101. 
Zou, S., Moldwin, M.B., Lyons, L.R., Nishimura, Y., Hirahara, M, Sakanoi, T., Asamura, K., Nicolls, M.J., Miyashita, Y., Mende, S.B., Heinselman, C.J., 2010. Identification of substorm onset location and preonset sequence using Reimei, THEMIS GBO, PFISR, and Geotail. J. Geophys. Res., 116, A00117. 
(a) 2008feb15_themisa: $41 \mathrm{keV}$

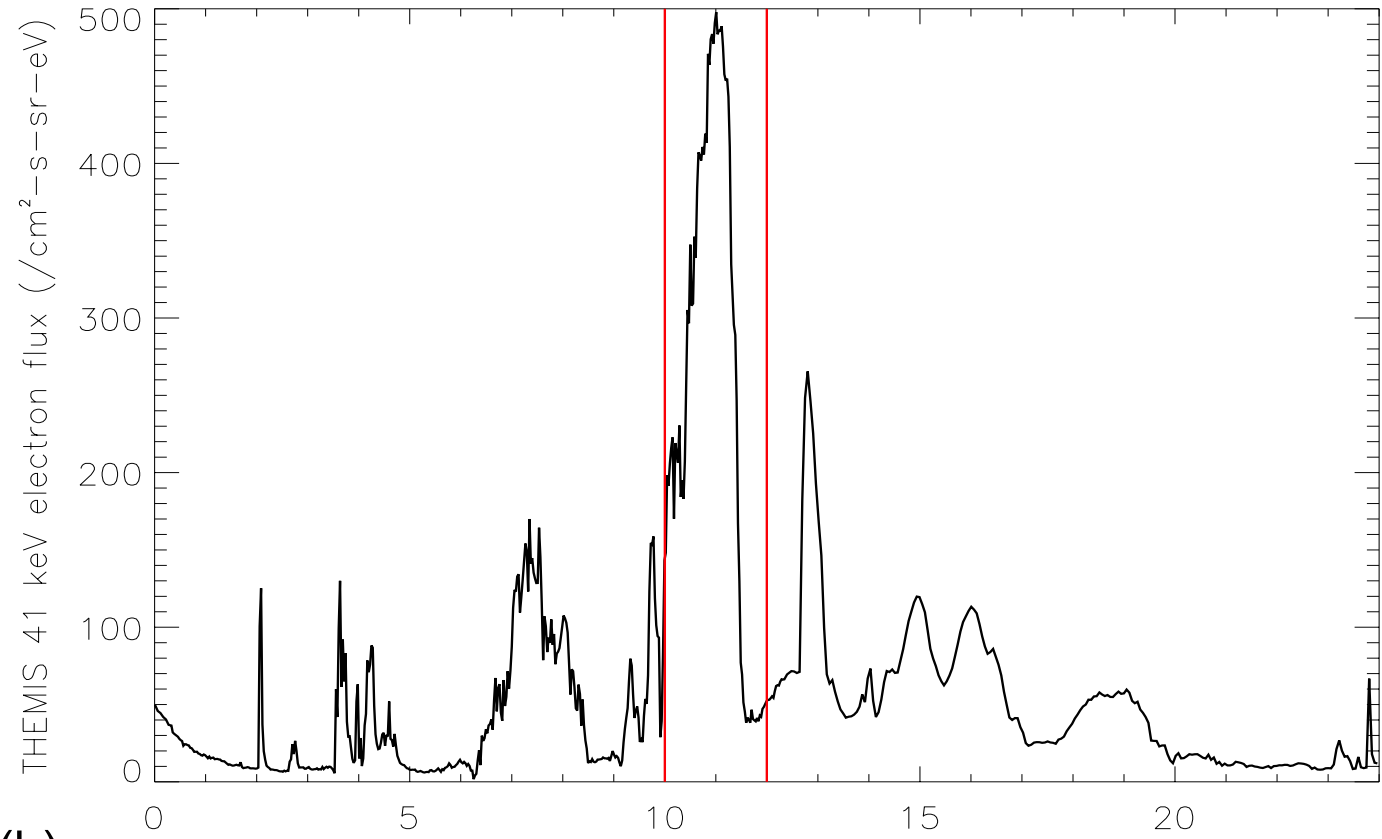

(b)

UT(hours)

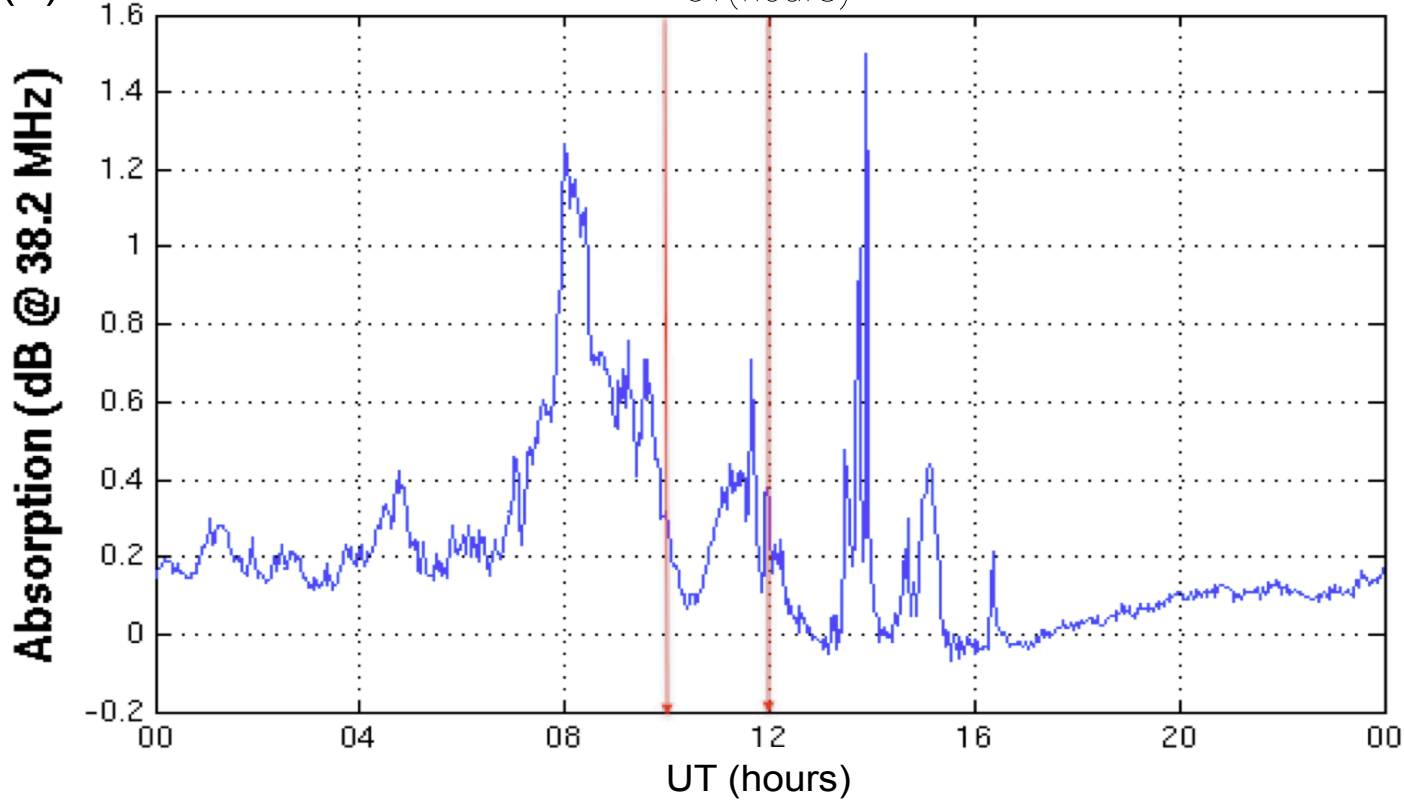

Figure 1: (a) THEMIS-A $41 \mathrm{keV}$ electron flux $\left(\mathrm{cm}^{-2} \cdot \mathrm{s}^{-1} \cdot \mathrm{sr}^{-1} \cdot \mathrm{eV}^{-1}\right)$ and (b) IRIS absorption (dB) on 2008 February 15. (Local noon at Kilpisjärvi is at 10.6 UT.) 

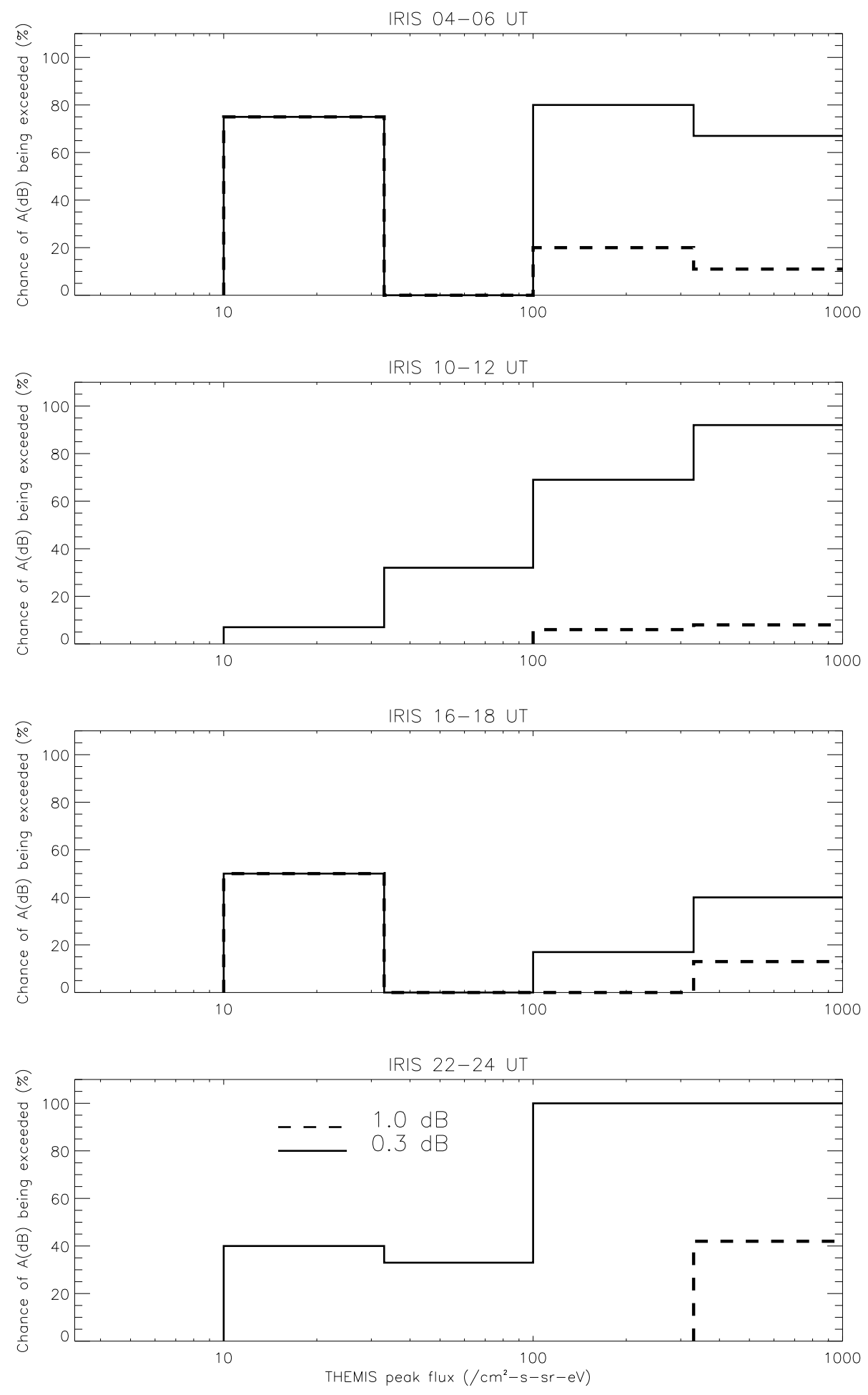

Figure 2: Probabilities of at least $0.3 \mathrm{~dB}$ and $1.0 \mathrm{~dB}$ in each of the four sectors for given ranges of $41 \mathrm{keV}$ THEMIS flux 


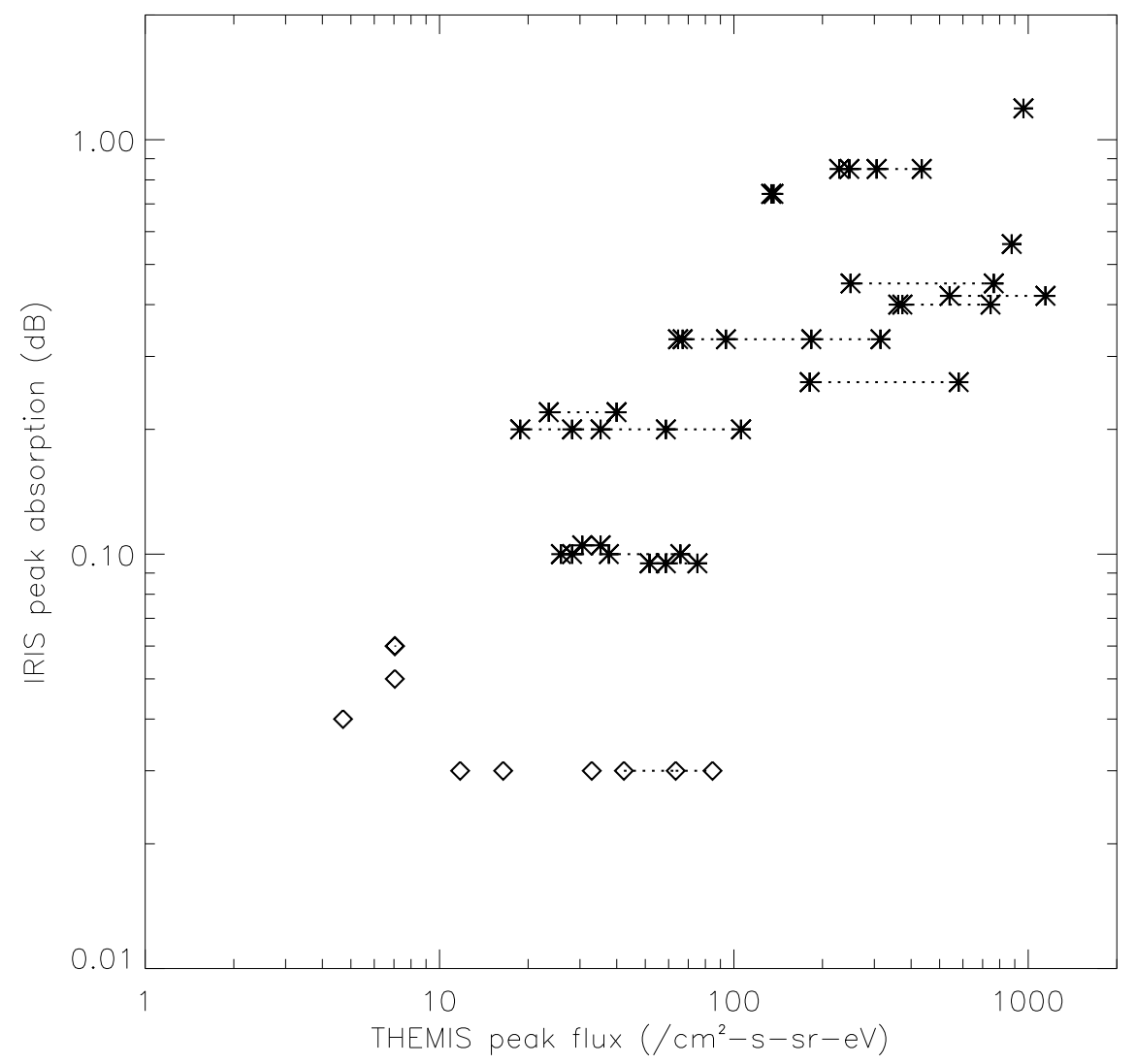

Figure 3: Peak absorption $(\mathrm{A} \mathrm{dB})$ against $41 \mathrm{keV}$ peak flux $\left(\mathrm{F} \mathrm{cm}^{-2} \cdot \mathrm{s}^{-1} \cdot \mathrm{sr}^{-1} \mathrm{eV}^{-1}\right)$ for all measurable values from the set of 42 days in the IRIS noon sector. (Groups of points at $0.1 \mathrm{~dB}$ have been offset in absorption, for clarity; values $<0.1 \mathrm{~dB}$ are indicated by diamonds) 
(a)
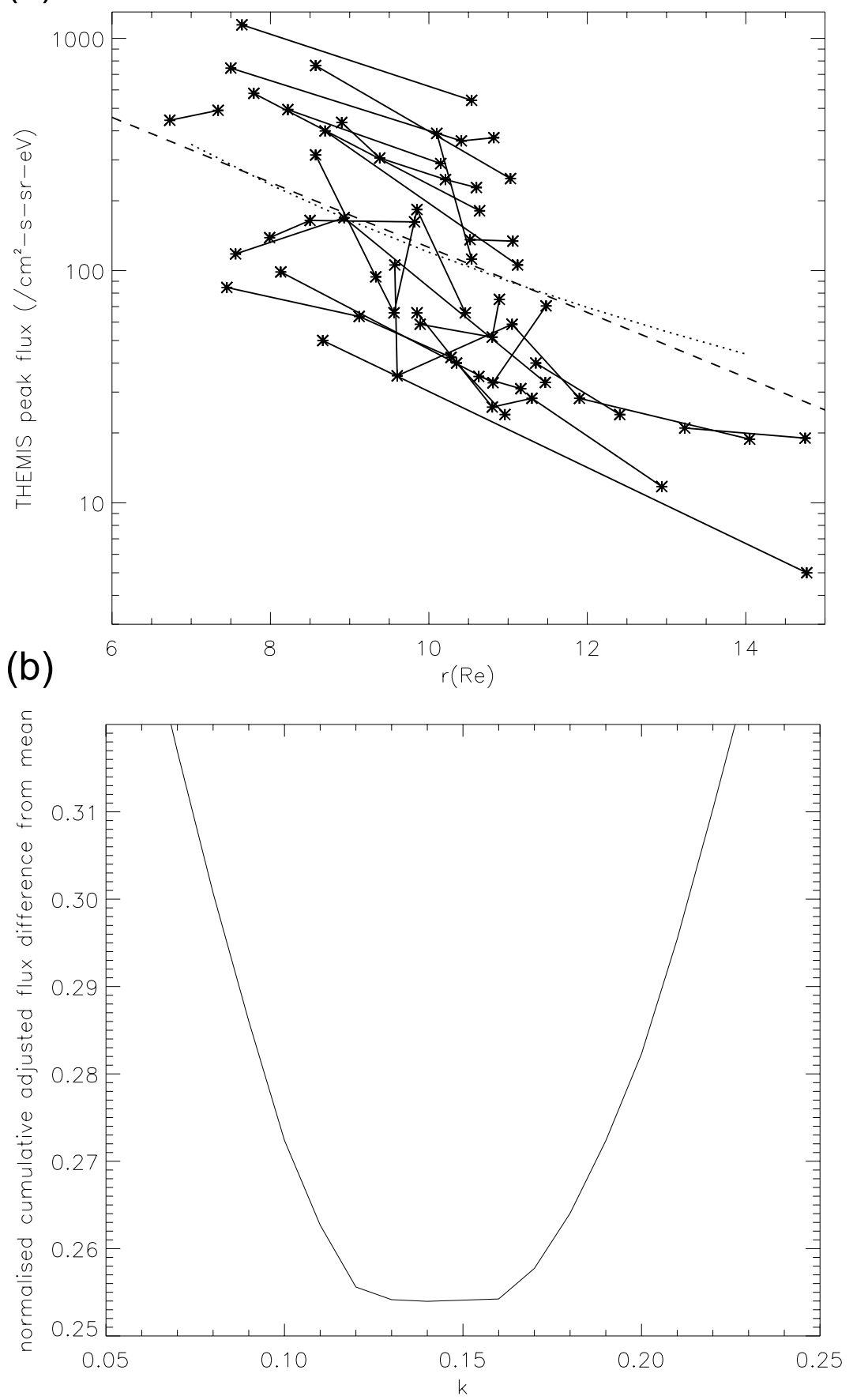

Figure 4: (a) Variation of $41 \mathrm{keV}$ flux with geocentric radial distance in the ecliptic plane for the 23 events observed by 2 or more satellites. (The dashed line has gradient $\mathrm{k}=-0.14$; the dotted line represents the relation $F \propto r^{-3}$.) (b) Variation of "normalised cumulative adjusted flux difference from the mean" against gradient $\mathrm{k}$. 
(a)

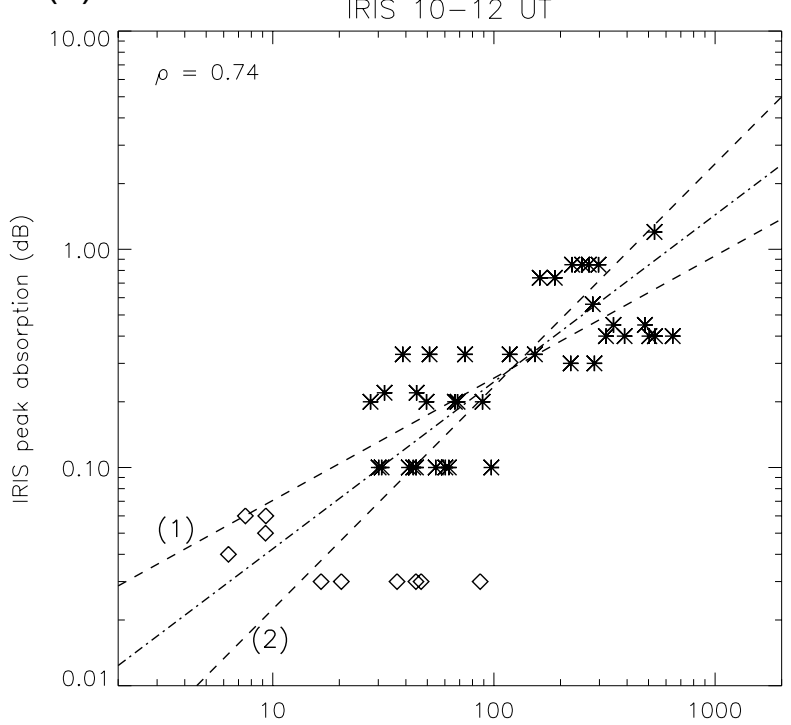

(c)

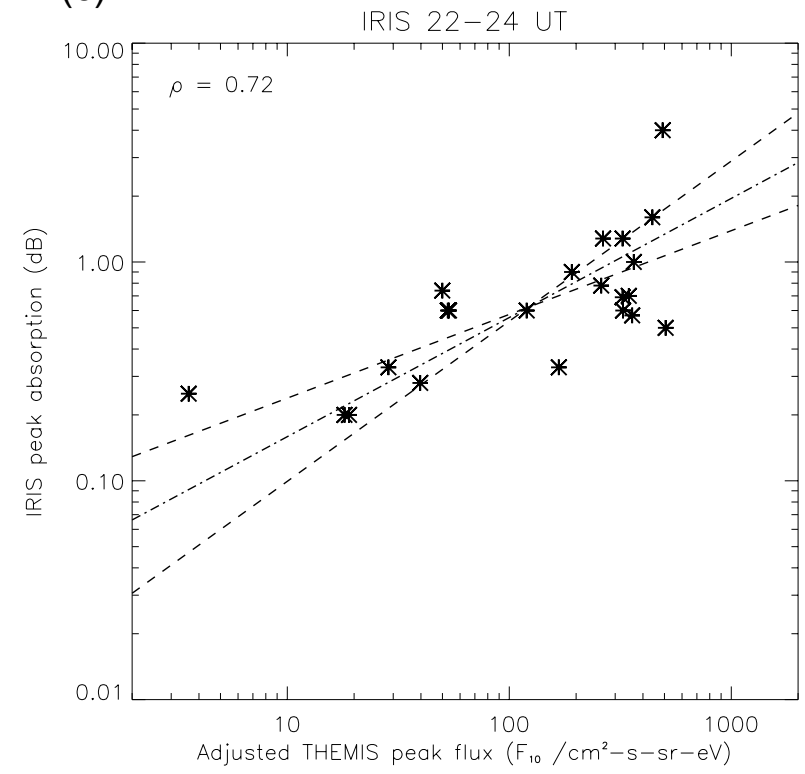

(b)

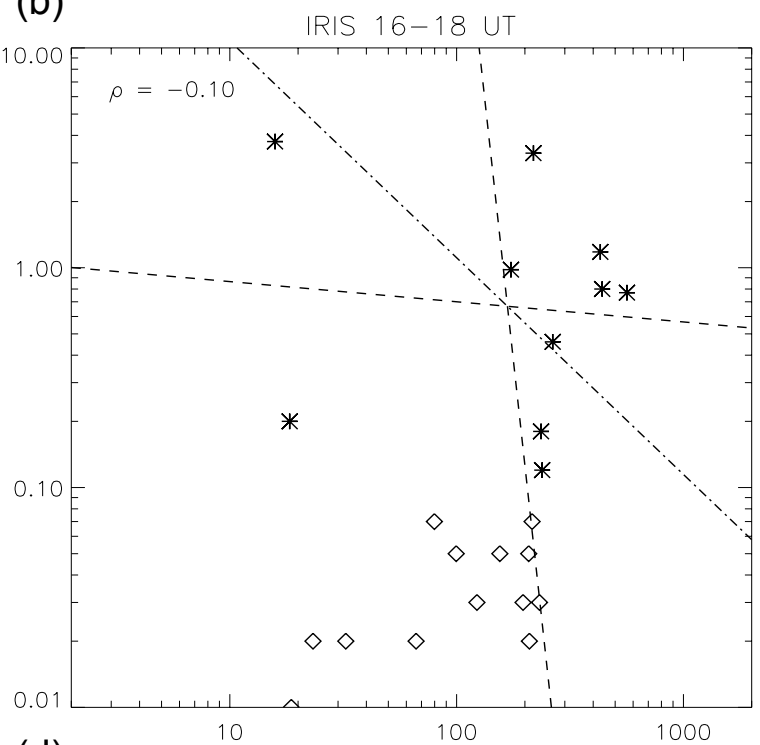

(d)

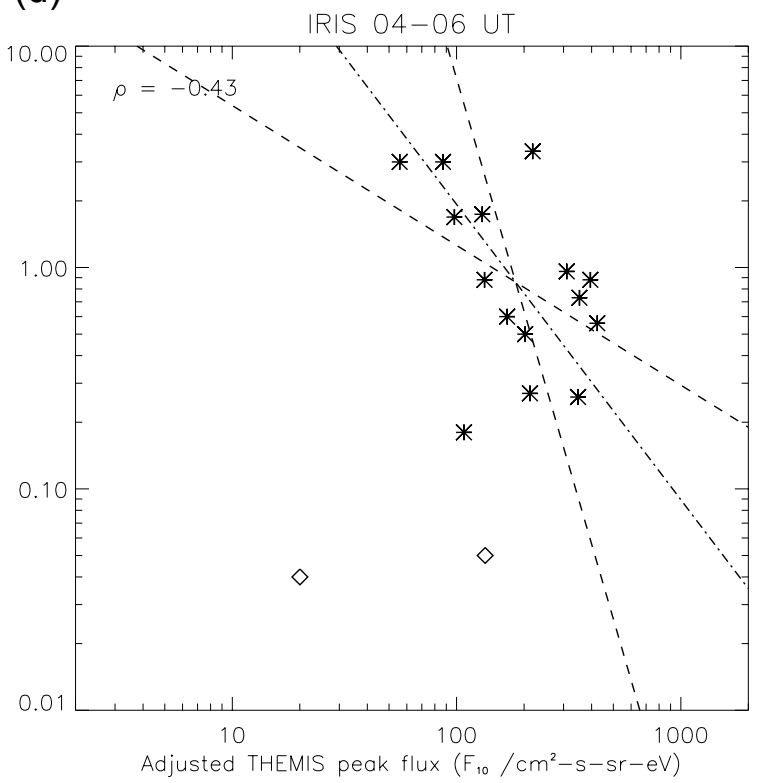

Figure 5: Variation of IRIS peak absorption (A) with THEMIS adjusted peak flux $\left(\mathrm{F}_{10}\right)$ for IRIS UT sectors: (a) 10-12; (b) 16-18; (c) 22-24; (d) 04-06. (Regression lines: (1) $\log (\mathrm{A})$ on $\log \left(\mathrm{F}_{10}\right) ;(2) \log \left(\mathrm{F}_{10}\right)$ on $\left.\log (\mathrm{A}).\right)$ 

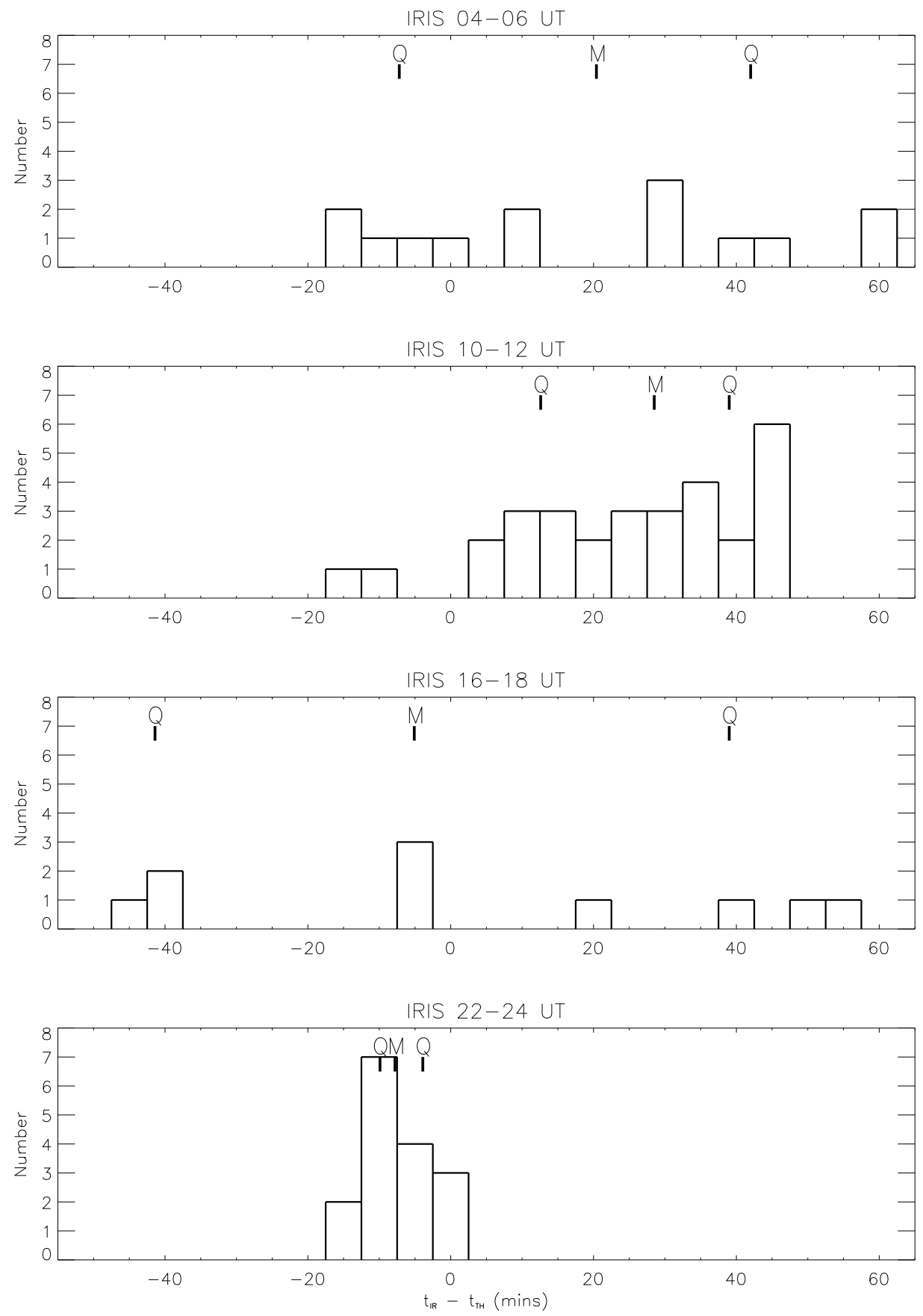

Figure 6: Summary of time differences $\left(\mathrm{t}_{I R}-\mathrm{t}_{T H}\right.$ minutes) for the four IRIS time sectors $(\mathrm{M}=$ median; $\mathrm{Q}=$ quartiles). 


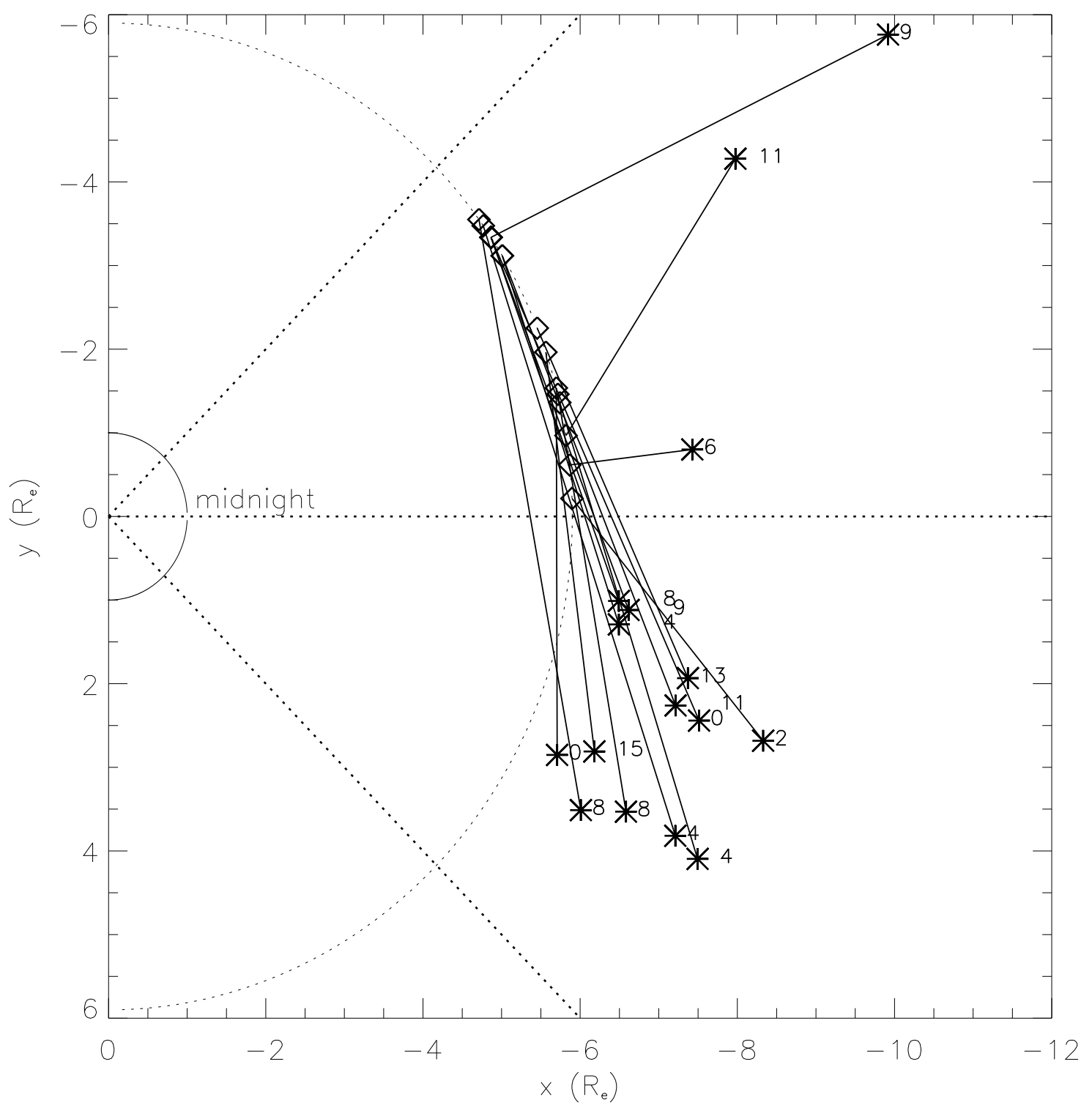

Figure 7: Comparison between nose of field line through Kilpisjärvi (diamonds, at L $=5.9$ ) and THEMIS satellite location (asterisks) for individual cases in the midnight sector. The time differences in minutes are marked (the absorption peak precedes the THEMIS flux). 


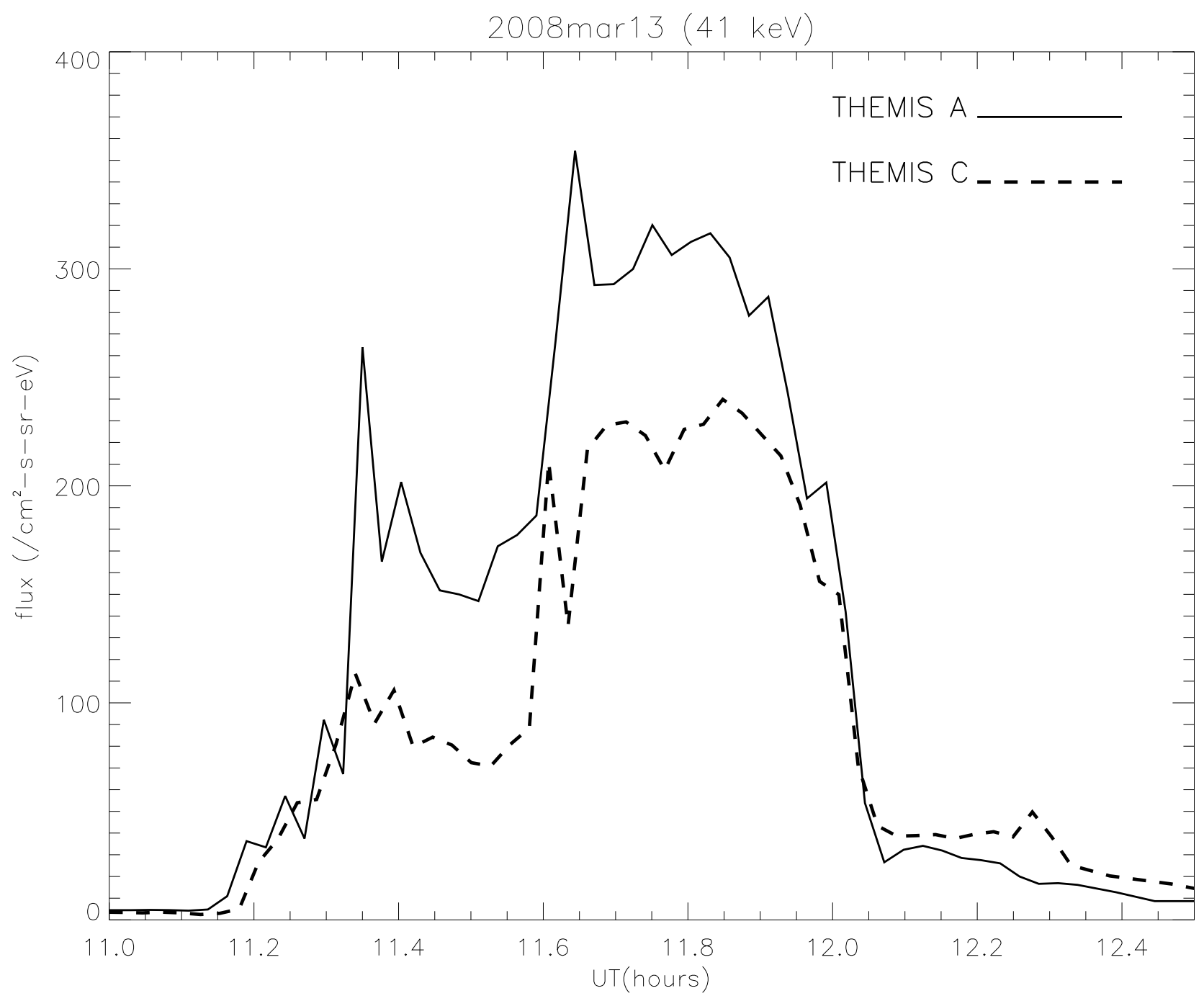

Figure 8: Comparison of $41 \mathrm{keV}$ THEMIS flux profiles between satellites A and $\mathrm{C}$ for an event on 2008 March 13, the satellites being $2.62 \mathrm{R}_{e}$ apart. 

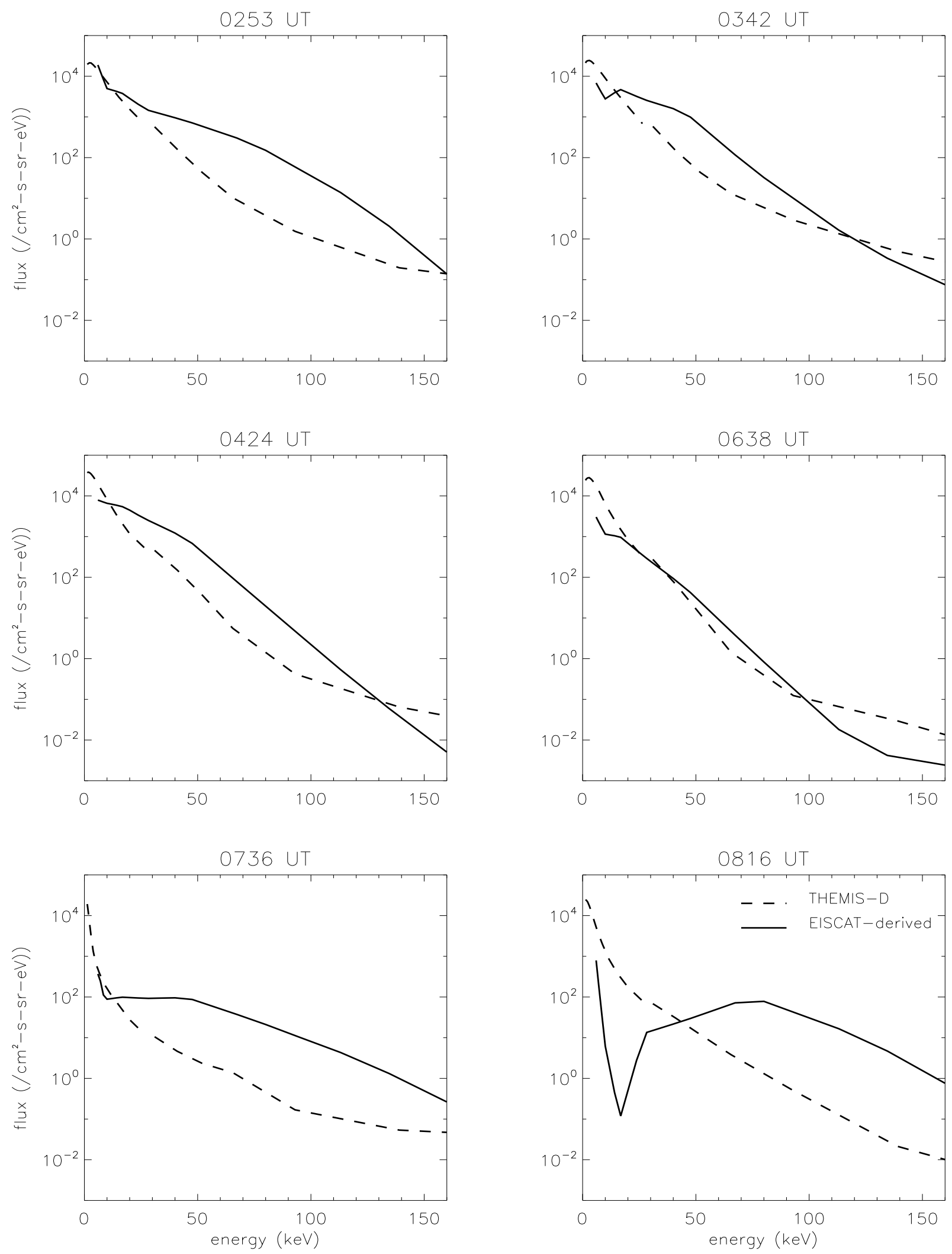

Figure 9: Comparison of THEMIS-D and EISCAT-derived spectra at selected times on the morning of March 92008 (solid lines: EISCAT-derived spectra; dashed lines: THEMIS-D spectra). 


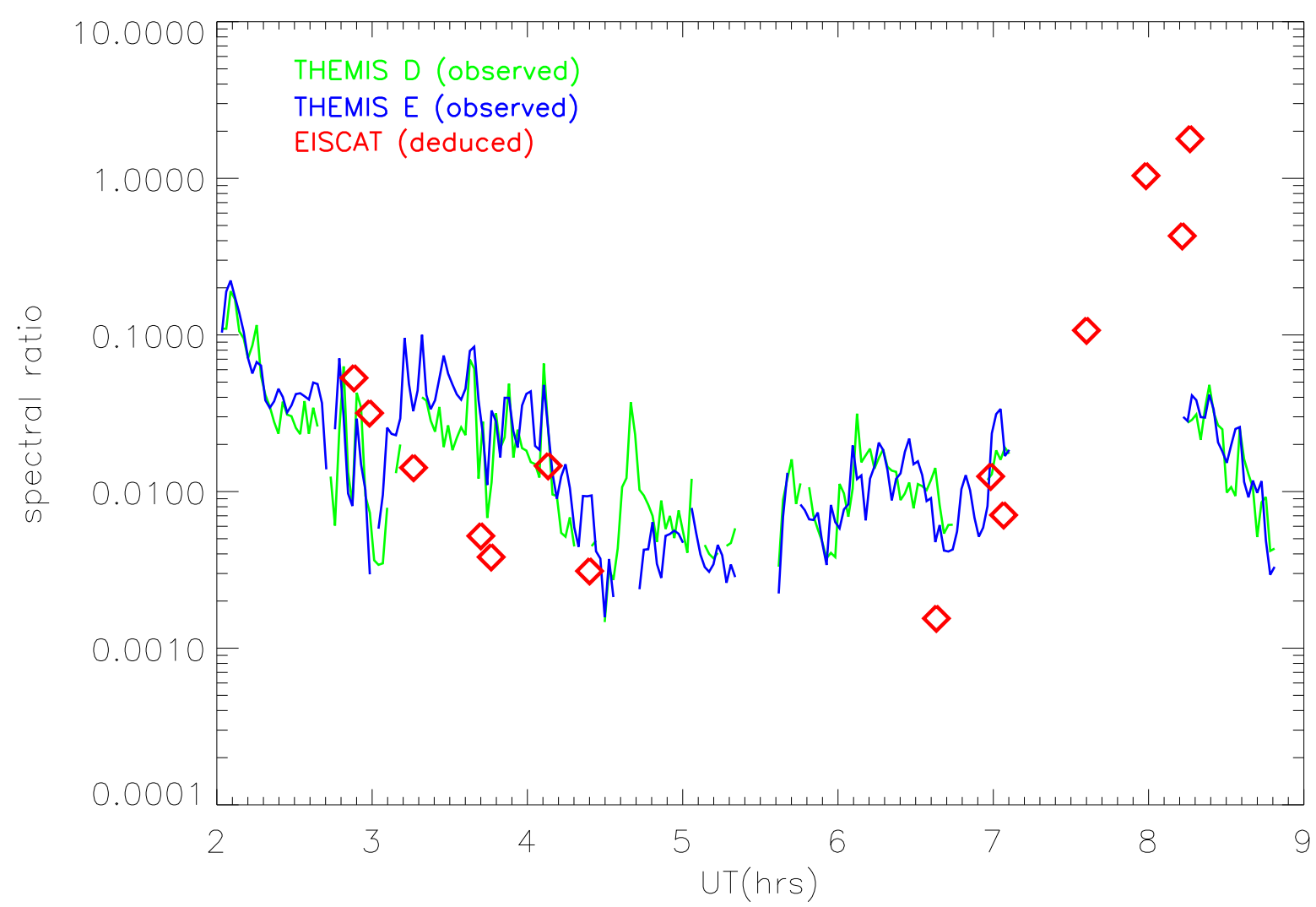

Figure 10: Comparison of spectral hardness: THEMIS D (green); THEMIS E (blue); EISCATdeduced (red). (Fluxes $<0.1 \mathrm{~cm}^{-2} \cdot \mathrm{s}^{-1} \cdot \mathrm{sr}^{-1} \cdot \mathrm{eV}^{-1}$ were discarded, which caused the gaps in the THEMIS profiles.) 


\begin{tabular}{|l|c|c|c|c|c|}
\hline IRIS UT range & $04-06$ & $10-12$ & $16-18$ & $22-24$ & Total \\
\hline \hline 1. Days considered & 52 & 42 & 46 & 54 & 194 \\
2. Days rejected due to belt contamination & 15 & 4 & 17 & 26 & 62 \\
3. Days without radiation belt contamination (1-2) & 37 & 38 & 29 & 28 & 132 \\
4. Days from (3) with measurable 41 keV flux event & 22 & 33 & 28 & 21 & 104 \\
5. Days from (4) with clearly associated abs event $\geq 0.1 \mathrm{~dB}$ & 16 & 18 & 12 & 20 & 66 \\
6. Days from (5) without associated magnetic substorm & 0 & 2 & 1 & 0 & 3 \\
\hline
\end{tabular}

Table 1: General occurrence statistics for the four IRIS sectors. (6. According to SME index (http://supermag.jhuapl.edu/substorms/)) 


\begin{tabular}{|c|c|c|c|c|c|}
\hline \multirow[t]{2}{*}{$\begin{array}{l}\text { Flux } \\
\text { range }\end{array}$} & \multirow[t]{2}{*}{$\begin{array}{l}\text { No. of } \\
\text { values }\end{array}$} & \multirow[t]{2}{*}{$\begin{array}{l}\text { Median } \\
\text { (dB) }\end{array}$} & \multirow[t]{2}{*}{$\begin{array}{l}\text { Range } \\
\text { (dB) }\end{array}$} & \multicolumn{2}{|c|}{$\begin{array}{c}\text { Chance }(\%) \text { of abs } \\
\text { being at least }\end{array}$} \\
\hline & & & & $1.0 \mathrm{~dB}$ & $0.3 \mathrm{~dB}$ \\
\hline \multicolumn{6}{|c|}{ IRIS 04-06 UT (18 samples) } \\
\hline$\geq 330$ & 9 & 0.50 & $0.00-3.35$ & 11 & 67 \\
\hline $100-330$ & 5 & 0.88 & $0.18-1.69$ & 20 & 80 \\
\hline $33-100$ & 0 & & & 0 & 0 \\
\hline $10-33$ & 4 & 3.00 & $0.04-3.00$ & 75 & 75 \\
\hline $3.3-10$ & 0 & & & 0 & 0 \\
\hline \multicolumn{6}{|c|}{ IRIS 10-12 UT (70 samples) } \\
\hline$\geq 330$ & 12 & 0.42 & $0.26-1.19$ & 8 & 92 \\
\hline $100-330$ & 16 & 0.70 & $0.20-1.00$ & 6 & 69 \\
\hline $33-100$ & 19 & 0.10 & $0.03-0.85$ & 0 & 32 \\
\hline $10-33$ & 14 & 0.10 & $0.02-0.50$ & 0 & 7 \\
\hline $3.3-10$ & 6 & 0.05 & $0.03-0.06$ & 0 & 0 \\
\hline $1.0-3.3$ & 3 & 0.05 & $0.05-0.05$ & 0 & 0 \\
\hline \multicolumn{6}{|c|}{ IRIS 16-18 UT (26 samples) } \\
\hline$\geq 330$ & 15 & 0.12 & $0.00-3.32$ & 13 & 40 \\
\hline $100-330$ & 6 & 0.05 & $0.00-0.46$ & 0 & 17 \\
\hline $33-100$ & 1 & 0.03 & $0.03-0.03$ & 0 & 0 \\
\hline $10-33$ & 2 & 3.75 & $0.01-3.75$ & 50 & 50 \\
\hline $3.3-10$ & 2 & 0.20 & $0.03-0.20$ & 0 & 0 \\
\hline \multicolumn{6}{|c|}{ IRIS 22-24 UT (24 samples) } \\
\hline$\geq 330$ & 12 & 0.90 & $0.50-4.00$ & 42 & 100 \\
\hline $100-330$ & 3 & 0.60 & $0.33-0.60$ & 0 & 100 \\
\hline $33-100$ & 3 & 0.28 & $0.00-0.74$ & 0 & 33 \\
\hline $10-33$ & 5 & 0.20 & $0.10-0.60$ & 0 & 40 \\
\hline $3.3-10$ & 1 & 0.25 & $0.25-0.25$ & 0 & 0 \\
\hline
\end{tabular}

Table 2: Detailed occurrence statistics for the four IRIS sectors (138 samples in total). 


\begin{tabular}{|c|c|c|c|c|c|c|c|}
\hline \multirow{2}{*}{ Correlated } & \multirow{2}{*}{12} & \multicolumn{3}{|c|}{$\begin{array}{c}22-24 \mathrm{UT} \\
(22 \text { values })\end{array}$} & \multicolumn{3}{|c|}{$\begin{array}{c}10-12 \mathrm{UT} \\
(29 \text { values })\end{array}$} \\
\cline { 3 - 8 } & 3 & $\rho_{12,3}$ & $\mathrm{z}$ & $\mathrm{u}$ & $\rho_{12,3}$ & $\mathrm{z}$ & $\mathrm{u}$ \\
\hline \hline $\log \mathrm{F}, \log \mathrm{A}$ & $\mathrm{r}$ & 0.56 & 0.63 & $0.4 \%$ & 0.69 & 0.84 & $<0.1 \%$ \\
$\log \mathrm{F}, \mathrm{r}$ & $\log \mathrm{A}$ & -0.69 & 0.85 & $<0.1 \%$ & -0.64 & 0.75 & $<0.1 \%$ \\
$\log \mathrm{A}, \mathrm{r}$ & $\log \mathrm{F}$ & 0.13 & 0.13 & $29 \%$ & 0.20 & 0.20 & $16 \%$ \\
\hline
\end{tabular}

Table 3: Results of partial correlation analysis of observed flux (F), strength of absorption (A), and radial distance of satellite (r) for IRIS sectors 22-24 UT and 10-12 UT. ( $\rho_{12,3}$ is the correlation coefficient between parameters 1 and 2 with parameter 3 partialled-out, and $u$ is the probability, based on Fisher's z-transform, that the correlation arose by chance.) 


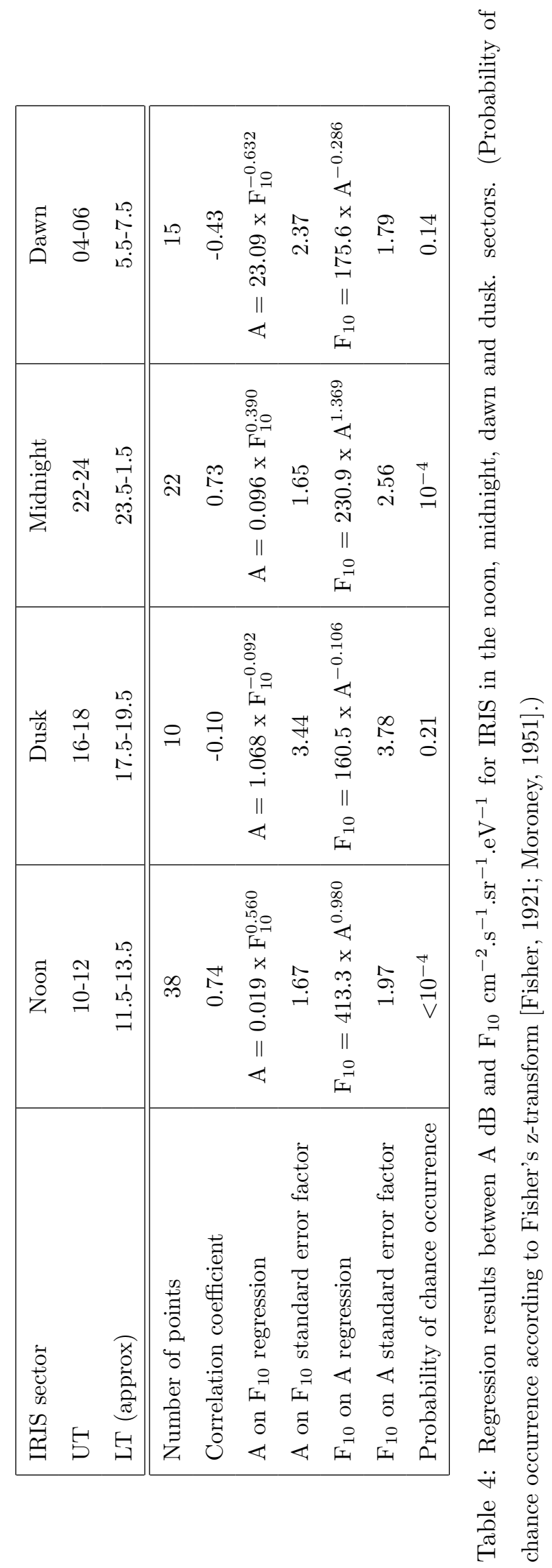




\begin{tabular}{|c|c|c|c|c|c|c|}
\hline $\begin{array}{c}\text { Absorption (A) } \\
\text { range }\end{array}$ & $\begin{array}{c}\text { No. of } \\
\text { values }\end{array}$ & $\begin{array}{c}\text { Median } \\
\text { flux }\end{array}$ & $\begin{array}{c}\text { Range } \\
\text { of flux }\end{array}$ & \multicolumn{3}{|c|}{$\begin{array}{c}\text { Chance (\%) of flux } \\
\text { being in range }\end{array}$} \\
\cline { 5 - 7 } & & & & $0-10$ & $10-100$ & $>100$ \\
\hline \hline $0.1 \leq \mathrm{A}<0.3$ & 6 & 3 & $0-10$ & 100 & 0 & 0 \\
$0.3 \leq \mathrm{A}<1.0$ & 12 & 140 & $0-400$ & 8 & 33 & 58 \\
$\mathrm{~A} \geq 1.0$ & 6 & 380 & $200-500$ & 0 & 0 & 100 \\
\hline
\end{tabular}

Table 5: Detailed occurrence statistics for the midnight IRIS sector, using absorption as the primary selection variable (24 samples in total). These flux values have not been adjusted to $10 \mathrm{R}_{e}$. 